\title{
Alarming Turn of Dengue Fever in Dhaka City in 2019
}

\author{
Arifa Akram \\ Medical Officer, Department of Virology, Institute of Epidemiology, Disease Control and Research (IEDCR), Dhaka, Bangladesh; \\ Email: drbarna43@gmail.com; Cell no.: +8801816296249
}

Dengue fever has re-emerged as a major public health challenge worldwide, with 2.5 billion people at risk of infection, more than 100 million cases and 25000 deaths being reported annually ${ }^{1}$. The dengue circumstances in Bangladesh is getting worse this year (2019) as the number of infected people has more than doubled since last month, compared with the same period last year ${ }^{2}$.

According to a report of Directorate General of Health Services of Ministry of Health \& Family Welfare, Dhaka, Bangladesh, 16223 people were infected with dengue in July and 9006 more till 6th August (Figure I) and 18 of them died ${ }^{3}$. A total of 10,148 people were infected with dengue last year and 26 of them died ${ }^{2}$.

Table 1: Dengue serotypes Status in Different Years $^{4}$

\begin{tabular}{|l|l|}
\hline Year & Dengue serotypes Status \\
\hline 2013 to 2016 & $\begin{array}{l}\text { DEN2 (predominant) followed } \\
\text { by DEN1 }\end{array}$ \\
\hline 2017 & $\begin{array}{l}\text { DEN 2 (predominant) followed } \\
\text { by DEN1 and co detection of } \\
\text { DEN 3 with DEN 2 (few cases) }\end{array}$ \\
\hline 2018 & $\begin{array}{l}\text { DEN 2 (predominant) followed } \\
\text { by DEN2 and DEN1 and co- } \\
\text { detection DEN2 \& DEN3 and } \\
\text { DEN1 \& DEN3(few cases) }\end{array}$ \\
\hline 2019 & $\begin{array}{l}\text { DEN 3 (predominant) followed } \\
\text { by co-detection of DEN2 \& } \\
\text { DEN3 and DEN1 \& DEN3 (few } \\
\text { cases) }\end{array}$ \\
\hline
\end{tabular}

Till now, dengue infections are believed to be caused by four antigenically distinct serotypes Dengue Virus DENV-1, DENV-2, DENV-3, and DENV-4; each generating a unique host immune response to the infection. These four serotypes are genetically similar and share approximately $65.0 \%$ of their genomes. The fifth variant DENV-5 has been isolated in October $2013^{1}$. Infection with one of the serotypes confers serotype-specific lifelong immunity; however, secondary infection with a heterogonous serotype often creates devastating outcomes, which may be due to antibody-dependent enhancement ${ }^{6}$.

Since 2000, Bangladesh has experienced dengue fever in every year. All four serotypes have been detected, with DENV-3 predominance until 2002. After that, during the years 2013 to 2016 a recent report showed that DENV-1 and DENV-2 are circulating serotypes in 3 major cities in Bangladesh, including Dhaka ${ }^{5}$. DENV-1 and DENV-2 are in circulation for more than a decade, thus, a large portion of the country's population might be immune to serotypes DENV-1, DENV-2 or both; however, they are at risk of developing severe dengue infection by DENV-3 or DENV-4. Thus, the high frequency of severe dengue cases in 2018 and 2019 correlates with the prevalence of serotype DENV-3 ${ }^{6}$.

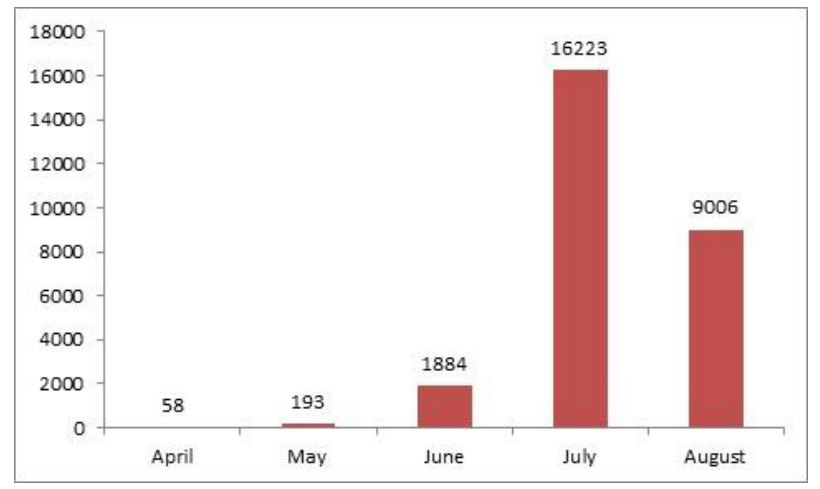

Figure I: Number of Affected people in 2019 
Most of the people who have been died due to dengue this year have been suffered from Dengue shock syndrome (DSS) and are infected in secondtime ${ }^{7}$. Dengue shock syndrome (DSS) is a dangerous complication from dengue which is often caused by a secondary infection with a different virus serotypes.

Experts have stated that effects of climate change, intermittent rain, pattern of weather and lack of cleanliness are the main reasons for this increase in dengue cases ${ }^{2}$.

Table 2: Year Wise Dengue Cases and Deaths in Bangladesh $^{4}$

\begin{tabular}{|l|c|c|}
\hline Year & No of Affected people & Death \\
\hline 2000 & 5551 & 93 \\
\hline 2001 & 2430 & 44 \\
\hline 2002 & 6282 & 58 \\
\hline 2003 & 486 & 10 \\
\hline 2004 & 3934 & 11 \\
\hline 2005 & 1048 & 4 \\
\hline 2006 & 2200 & 11 \\
\hline 2007 & 466 & 0 \\
\hline 2008 & 1153 & 0 \\
\hline 2009 & 474 & 0 \\
\hline 2010 & 409 & 0 \\
\hline 2011 & 1359 & 6 \\
\hline 2012 & 671 & 1 \\
\hline 2013 & 1749 & 2 \\
\hline 2014 & 375 & 0 \\
\hline 2015 & 3162 & 6 \\
\hline 2016 & 6060 & 14 \\
\hline 2017 & 2769 & 8 \\
\hline 2018 & 10148 & 26 \\
\hline $2019\left(\right.$ Upto $^{\text {th }}$ & 16223 & 18 \\
\hline August) & & \\
\hline & & \\
\hline
\end{tabular}

Directorate General of Health Services of Ministry of Health \& Family Welfare, Dhaka, Bangladesh conducted a survey and found the high presence of
Aedes mosquito in the capital. The survey has been found high level of larvae of Aedes mosquito in water collected from abandoned tyres, plastic drums, buckets, open tanks in under-construction buildings and flower tubs ${ }^{2}$.

Although having 19 years' knowledge of dengue management, the unfortunately large number of deaths indicates that urgent awareness is required to strengthen the early detection of dengue at all healthcare facilities. Except it, public health management like a vector control programme, awareness regarding prevention and regular surveillance are very important.

\section{References}

1. Mustafa MS, Rasotgi V, Jain S, Gupta V. Discovery of fifth serotype of dengue virus (DENV-5): A new public health dilemma in dengue control. Medical Journal Armed Forces India 2015;71(1):67-70.

2. The daily star. Dengue situation in Bangladesh takes alarming turn. Available at: https://www.thedailystar.net /backpage/ news/dengue-situation-in-bangladesh-takesalarming-turn-1761832? Accessed on July 17, 2019

3. Dengue, control room dengue dashboard. Available at: http://103.247.238.81/webportal/_ pages/controlroom dengue_dashboard.php Accessed on August 06, 2019

4. IEDCR. Dengue situation update, 05082019. Available at: https://www.iedcr.gov.bd/ Accessed on: August 05, 2019.

5. Muraduzzaman AK, Alam AN, Sultana S, Siddiqua M, Khan $\mathrm{MH}$, Akram A, et al. Circulating dengue virus serotypes in Bangladesh from 2013 to 2016. Virus disease 2018;29(3):303-7 6. Shirin T, Muraduzzaman AK, Alam AN, Sultana S, Siddiqua M, Khan MH, et al. Largest dengue outbreak of the decade with high fatality may be due to reemergence of DEN-3 serotype in Dhaka, Bangladesh, necessitating immediate public health attention. New microbes and new infections. 2019;29:100511

7. The daily star. Dengue deaths so far: most were infected a second time. Available at:

https://www.thedailystar.net/frontpage/max-people-dieddengue-fever-in-bangladesh-infected-for-second-time-1782226 Accessed on August 06, 2019

[Bangladesh Journal of Infectious Diseases June 2019;6(1):12]

Cite this article as: Akram A. Alarming Turn of Dengue Fever in Dhaka City in 2019. Bangladesh J Infect Dis 2019;6(1):1-2 